\title{
Assessment of the Need for Dental Treatment Resulting From Dental Trauma in 12-Year-Old Brazilian Schoolchildren: A Cross-Sectional Study
}

\author{
Haroldo Neves de Paiva1 ${ }^{(}$, Cibelly Mara Pereira Araújo ${ }^{1}$, Kayke Braulio Silva1 ${ }^{1}$, Talita Torquato

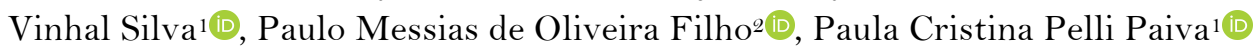

\begin{abstract}
${ }^{1}$ Department of Dentistry, Faculty of Biological and Health Sciences, Federal University of Vales do Jequitinhonha and Mucuri, Diamantina, MG, Brazil.

2Department of Basic Sciences, Faculty of Biological and Health Sciences, Federal University of Vales do Jequitinhonha and Mucuri, Diamantina, MG, Brazil.
\end{abstract}

Author to whom correspondence should be addressed: Paula Cristina Pelli Paiva, Department of Dentistry, Faculty of Biological and Health Sciences, Federal University of Vales do Jequitinhonha and Mucuri, Rua da Glória, 187, Center, Diamantina, MG, Brazil.39100-000. Phone: +55 38 35326000. E-mail: paula.paiva@ufvjm.edu.br.

Academic Editors: Alessandro Leite Cavalcanti and Wilton Wilney Nascimento Padilha

Received: 06 August 2019 / Accepted: 17 April 2020 / Published: 08 May 2020

\begin{abstract}
How to cite this article: Paiva HN, Araújo CMP, Silva KB, Silva TTV, Oliveira Filho PM, Paiva PCP. Assessment of the need for dental treatment resulting from dental trauma in 12-year-old Brazilian schoolchildren: a cross-sectional study. Pesqui Bras Odontopediatria Clín Integr. 2020; 20:e5 105. https://doi.org/10.1590/pboci.2020.078
\end{abstract}

\begin{abstract}
Objective: To identify the need for restorative treatment in 12-year-old Brazilian schoolchildren with dental trauma and its association with clinical and socioeconomic factors. Material and Methods: A crosssectional population-based study was carried out with sample composed of 588 12-year-old students from the city of Diamantina, Minas Gerais, Brazil. Data were collected from August to November 2016 through clinical examination, adopting the Andreasen classification and semi-structured questionnaire to verify the etiology and location of the accident that resulted in dental trauma. Statistical analysis included the frequency distribution and bi and multivariate analysis, with $5 \%$ significance level. Results: The presence of 219 traumatized teeth in 176 students was observed (29.9\%). The main lesion was enamel fracture (41.4\%), followed by enamel and dentin fracture (39.4\%). The presence of restorative treatment was observed only in $11.5 \%$ of students. Fall (43.5\%) was the most frequent etiology, followed by accidents on the streets (35.8\%). Need for treatment was present in $53.4 \%$ of adolescents. Statistically significant association between males $(\mathrm{p}=0.010)$, severe overjet $(\mathrm{p}<0.0001)$ and inadequate lip protection $(\mathrm{p}<0.0001)$ and presence of dental trauma was observed. Maternal schooling over 8 years of study was statistically associated with need for restorative treatment $(\mathrm{OR}=2.047$; CI: 1.099-3.813; $\mathrm{p}=0.023)$. Conclusion: Prevalence of dental trauma, need for restorative treatment and number of adolescents with no access to restorative treatment in this study were high, point out that the health system is unable to satisfactorily prevent dental trauma and absorb all dental treatment demand resulting from dental trauma.
\end{abstract}

Keywords: Epidemiology; Oral Health; Tooth Injuries; Tooth Fractures. 


\section{Introduction}

Among oral alterations, dental trauma stands out as one of the most serious public health problems in children and adolescents, with high prevalence and high psychosocial impact [1-3]. Dental trauma can be defined as any injury of thermal, chemical or physical nature that affects teeth, of varying intensity, severity and extension and can be recognized from a small enamel fracture to the complete loss of the dental element, which origin can be accidental or intentional [1].

Individuals affected by dental trauma can present numerous changes such as loss of structure, sensitivity and tooth mobility, root resorption, changes in dental crown color and pulp necrosis. The consequences and sequelae of a traumatized tooth can take long time to manifest, and the healing and repair process does not occur immediately after the accident [1,4].

The main etiologies of dental trauma are falls, collisions with objects or people, automobile accidents, sports practices and violence [5], with the majority of studies pointing out that falls and collisions are more prevalent [6-9]. The location of the occurrence of dental trauma varied according to local or cultural habits. Environmental, behavioral factors, socioeconomic status and architecture of parks and schools play an important role in the etiology of dental injuries [6], with home, street or school being the main locations reported in literature [6,9-11].

Clinical factors such as lip coverage and horizontal overjet of teeth have also been identified as predisposing to dental trauma. Lip covering is responsible for protecting the teeth by absorbing and cushioning possible impacts during a collision. Thus, individuals with inadequate lip coverage and greater horizontal overjet would be more likely of suffering traumatic injuries to anterior teeth [1,12].

The immediate need for treatment aims to ensure pain control, restoration of function, aesthetics and prevention of social and psychological consequences for children and adolescents affected by dental trauma [13]. Studies have suggested that dental trauma is often not properly treated, being often neglected as an emergency care [14]. The high cost of initial care and the need for patient proservation, in some cases for a longer period of time, stands out $[15,16]$.

In recent years, several studies have investigated the prevalence of dental trauma and associated factors, highlighting the importance of its knowledge for planning health policies, but few have evaluated the presence of dental treatment for traumatized teeth or its need. Therefore, the aim of the present study was to investigate the need for restorative dental treatment due to dental trauma and associated factors in 12-year-old adolescents in the city of Diamantina, Minas Gerais, Brazil

\section{Material and Methods}

Study Design and Sample Characterization

The present study was carried out in the municipality of Diamantina, located in northeastern state of Minas Gerais, with approximately 46,372 inhabitants. The municipality has literacy rate of $83.4 \%$ and Human Development Index (HDI) of 0.716, being considered by the United Nations Development Program (UNDP) as having the best index among cities belonging to the Vale do Jequitinhonha region of Minas Gerais [17].

This cross-sectional population-based study was carried out between August and November 2016 and aimed at adolescents aged 12 years enrolled in elementary schools of the urban area. Adolescents were randomly selected from public and private schools. For sample calculation, maximum population variability (0.25) was used with 95\% confidence level, $\mathrm{Z} \alpha / 2=1.96 ; 4 \%$ estimation error, $\mathrm{d}=0.03$. The minimum sample size calculated was 546 , adding $10 \%$ to compensate for possible losses, totaling 601 adolescents. 
The age of 12 years was chosen because it is the age recommended by the World Health Organization [18] to represent the population of adolescents in oral health epidemiological studies, which coincide with the end of the period of mixed dentition and being the age of greatest incidence of dental trauma 1, enabling comparison among studies.

\section{Data Collection}

Authorizations for the conduction of the study were obtained from Municipal and State Health and Education Secretariats. Subsequently, pre-scheduled visits were made to all participating schools requesting the collaboration of the board, teachers and supervisors. Awareness-raising lectures were held in classrooms, highlighting the importance of participation and consent of students and their guardians through the signing of the informed consent form and assent form, explaining the importance of participation and the conduction of epidemiological studies and knowledge of possible results in order to achieve changes and improvements on the behalf of the community.

Information about socioeconomic status was collected through maternal schooling in years of study and family income through the sum of all wages received by economically active members living with the adolescent, divided by the current minimum wage. For statistical purposes, maternal schooling was dichotomized in up to eight years of study and above eight years, coinciding with the end of elementary school and the average years of study of the Brazilian population [17]. Family income was dichotomized by the median. The questionnaire with questions related to socioeconomic status was sent to parents / guardians of adolescents together with the informed consent form (ICF). For results to be correlated and guarantee secrecy and confidentiality of data, clinical file and questionnaires were coded.

Prior to data collection, the methodology was tested in a pilot study with a convenience sample of 101 12-year-old students who did not participate in the main study. In the pilot study, the examiner was trained by an expert in dental trauma, and at this moment, all doubts regarding trauma classification and variables involved were resolved. No changes to the proposed methodology were necessary.

On a day previously scheduled with the school management, a room was reserved for data collection. The team consisted of an examiner, dentist with solid clinical experience, previously trained and calibrated for the diagnosis of dental trauma, need for restorative treatment and clinical variables (Kappa 0.79 and 0.88 ), a note taker, who filled out data and an assistant who took students to the examination site. Sex and date of birth were recorded during clinical examination and confirmed by school records. The environment had good natural lighting, as well as artificial lighting with continuous-flow Petzl lamp.

For the clinical examination, the student was seated in front of the examiner. Teeth were dried and cleaned with sterile gauze and through clinical mirror, all permanent incisors were examined. Periodontal probe was used to assist in the removal of possible residues and to evaluate the presence and quality of restorations [1] and to measure the horizontal overjet, which was considered to be accentuated above $5 \mathrm{~mm}$. Lip protection was observed without adolescents realizing it, while answering the questions asked by the examiner. All instruments were sterilized in accordance with biosafety guidelines and in sufficient amount for one day of examination ( \pm 25 examinations per day).

Andreasen's classification [1] was adopted to assess the presence of dental trauma. When the presence of trauma was detected, the adolescent was asked about its etiology, location of the accident, time since trauma, if there was any assistance and, if so, what type of assistance. The need for restorative treatment was also assessed. All adolescents with dental trauma were referred for restorative treatment and proservation at the Dental Traumatism Clinic of the Dentistry Course, Federal University of Vales do Jequitinhonha and Mucuri. 
Statistical Analysis

Data analysis was performed using the SPSS Statistical Package for the Social Sciences (SPSS for Windows, version 19.0, SPSS Inc, Chicago, IL, USA) and included frequency distribution and association tests. Statistical significance for the association between need for restorative treatment due to dental trauma and independent variables in the bivariate analysis was determined using the chi-square test $(\mathrm{p}<0.05)$.

\section{Ethical Principles}

The research project was submitted to and approved by the Ethics Committee for Research with human being of the Federal University of Vales do Jequitinhonha and Mucuri (Protocol No. 1.597.571). Adolescents received the Free and Informed Consent Form addressed to parents / guardians and also the Assent Form directed addressed to adolescents themselves, according to principles established by Brazilian Resolution 466/12. Only adolescents authorized by parents / guardians and who agreed to participate participated in the study.

\section{Results}

The final sample consisted of 588 students, representing $97.8 \%$ participation, of these, 176 had dental trauma, which represented prevalence of $29.9 \%$ with 219 traumatized teeth. Most adolescents had only one traumatized tooth (Table 1), with upper central incisors being the most affected $(\mathrm{n}=182 ; 83.9 \%)$, with no statistical difference between right and left sides $(\mathrm{p}=0.965)$.

Table 1. Frequency distribution of students with traumatized teeth.

\begin{tabular}{ccc}
\hline Number of Traumatized Teeth & N & \% \\
\hline One & 138 & 78.4 \\
Two & 33 & 18.7 \\
Three & 04 & 2.3 \\
Four & 01 & 0.6 \\
\hline
\end{tabular}

One hundred and twenty of adolescents with dental trauma (68.2\%) had horizontal overjet greater than $5 \mathrm{~mm}$ and $136(77.3 \%)$ had inadequate lip protection.

The most prevalent alteration in the first fractured tooth was enamel fracture and $/$ or $\operatorname{crack}(\mathrm{n}=77$; $35.5 \%)$, followed by enamel / dentin fracture without pulp exposure ( $\mathrm{n}=71 ; 32.7 \%)$. The most common alteration in the second tooth was enamel / dentin fracture without pulp exposure, followed by enamel fracture and / or crack. In the third fractured tooth, the most common alteration was enamel / dentin fracture without pulp exposure. Although 219 traumatized teeth were observed, only 25 (11.4\%) had restorative treatment (Table 2).

Table 2. Distribution of dental trauma according to the number of traumatized teeth.

\begin{tabular}{lccc}
\hline \multicolumn{1}{c}{ Type of Dental Trauma } & \multicolumn{2}{c}{ Number of Traumatized Teeth } \\
& One & Two & Three \\
& $\mathrm{N}(\%)$ & $\mathrm{N}(\%)$ & $\mathrm{N}(\%)$ \\
\hline Enamel Fracture and / or Crack & $77(35.1)$ & $12(5.5)$ & $1(0.4)$ \\
Enamel / Dentin Fracture without Pulp Exposure & $71(32.7)$ & $17(7.8)$ & $2(0.8)$ \\
Enamel / Dentin Fracture with Pulp Exposure & $3(1.4)$ & $0(0.0)$ & $1(0.4)$ \\
Lateral Dislocation & $1(0.4)$ & $0(0.0)$ & $0(0.0)$ \\
Intrusive Dislocation & $6(2.8)$ & $1(0.4)$ & $1(0.4)$
\end{tabular}




\begin{tabular}{rccc} 
Color Change & $1(0.4)$ & $0(0.0)$ & $0(0.0)$ \\
Restoration Due to Trauma & $17(7.8)$ & $8(3.7)$ & $0(0.0)$ \\
Total & 176 & 38 & 5 \\
\hline
\end{tabular}

Most adolescents (52.4\%) did not inform or did not remember the period of the day when trauma occurred. Of the 82 adolescents (46.6\%) who could answer, 51 (62.2\%) reported the afternoon, $16(19.5 \%)$ the morning and $15(18.3 \%)$ the evening. The main etiological factor was fall $(n=40 ; 43.5 \%)$ followed by playing with others $(\mathrm{n}=16 ; 17.4 \%)$, on the streets $(\mathrm{n}=33 ; 35.8 \%)$. Fifty-nine adolescents $(33.5 \%)$ were able to inform the time elapsed from the accident, with the majority reporting that it occurred more than a year ago. Only 39 adolescents $(22.2 \%)$ received dental care after dental trauma and 105 adolescents $(59.7 \%)$ did not receive any type of care / follow-up.

The need for restorative treatment was present in 94 adolescents $(53.4 \%)$. Of these, $56(59.6 \%)$ were male, $91(96.8 \%)$ attended public schools. Seventy-six adolescents (43.1\%) declared family income below 3 minimum wages.

Severe horizontal overjet ( $\geq 5 \mathrm{~mm}$ ) was present in 59 adolescents $(62.7 \%)$ and most had inadequate lip protection $(\mathrm{n}=62 ; 45.6 \%)$. Of the 176 adolescents who suffered dental trauma, 94 $(56.4 \%)$ needed restorative treatment. Of these, $42.6 \%$ needed restorations in composite resin and $9.65 \%$ needed endodontic treatment prior to resin restoration.

Table 3 shows the results of the association test between need for restorative treatment due to dental trauma and independent variables. In the study sample, only maternal schooling over 8 years of study (Complete Elementary School) $(\mathrm{OR}=2.047$; CI: 1.099-3.813; $\mathrm{p}=0.023)$ was associated with need for treatment.

Table 3. Dental trauma distribution and need for treatment according to clinical and socioeconomic factors.

\begin{tabular}{|c|c|c|c|c|c|c|}
\hline \multirow[b]{2}{*}{ Variables } & \multicolumn{2}{|c|}{ Dental Trauma } & \multicolumn{4}{|c|}{ Need for Treatment } \\
\hline & $\begin{array}{c}\text { Yes } \\
\text { N (\%) }\end{array}$ & $\begin{array}{c}\text { No } \\
\text { N }(\%)\end{array}$ & p-value & $\begin{array}{c}\text { Yes } \\
\text { N (\%) }\end{array}$ & $\begin{array}{c}\text { No } \\
\text { N (\%) }\end{array}$ & p-value \\
\hline \multicolumn{7}{|l|}{ Sex } \\
\hline Female & $76(25.2)$ & $226(74.8)$ & $0.010^{*}$ & $38(50.0)$ & $38(50.0)$ & 0.429 \\
\hline Male & $100(35.0)$ & $186(65.0)$ & & $56(56.0)$ & $44 \cdot(44.0)$ & \\
\hline \multicolumn{7}{|l|}{ Maternal Schooling } \\
\hline$\geq 8$ Years of Study & $106(28.2)$ & $270(71.8)$ & 0.237 & $49(46.2)$ & $57(53.8)$ & $0.023^{*}$ \\
\hline$<8$ Years of Study & $69(32.9)$ & $141(67.1)$ & & $44(63.8)$ & $25(36.2)$ & \\
\hline \multicolumn{7}{|l|}{ Family Income** } \\
\hline < 3 Minimum Wages & $135(30.5)$ & $307(69.5)$ & 0.605 & $76(56.3)$ & $59(43.7)$ & 0.164 \\
\hline z 3 Minimum Wages & $41(28.3)$ & $104(71.7)$ & & $18(43.9)$ & $23(56.1)$ & \\
\hline \multicolumn{7}{|l|}{ Horizontal Overjet } \\
\hline$<5 \mathrm{~mm}$ & $120(23.9)$ & $383(76.1)$ & $<0.0001^{*}$ & $59(49.2)$ & $61(50.8)$ & 0.099 \\
\hline$\geq 5 \mathrm{~mm}$ & $56(65.1)$ & $30(34.9)$ & & $35(62.5)$ & $21(37.5)$ & \\
\hline \multicolumn{7}{|l|}{ Lip Protection } \\
\hline Adequate & $40(12.6)$ & $277(87.4)$ & $<0.0001^{*}$ & $20(50.0)$ & $20(50.0)$ & 0.623 \\
\hline Inadequate & $136(50.2)$ & $135(49.8)$ & & $74(54.4)$ & $62(45.6)$ & \\
\hline
\end{tabular}

\section{Discussion}

The present study showed prevalence of dental trauma of $29.9 \%$ among adolescents aged 12 years. This result is higher than studies carried out in Biguaçu, Herval D'Oeste and Palhoça, cities located in southern Brazil, which showed prevalence of $10.7 \%, 17.3 \%$ and $22.5 \%$, respectively, in adolescents with the 
same average age $[1,19,20]$. However, this prevalence was similar to study carried out in Montes Claros, in the northeastern region of the state of Minas Gerais, Brazil, using the same methodology, finding prevalence of $34.9 \%$ [10]. This variation in prevalence can be attributed to cultural aspects peculiar to each population and also to the lack of methodological standardization.

The most frequent lesion was enamel fracture followed by enamel and dentin fracture without pulp exposure. These results are in accordance with national epidemiological studies that also reported enamel fractures as the most prevalent [1,3,9,13]. According to literature, teeth most commonly affected in dental trauma are upper central incisors, lower central incisors, lower lateral incisors and upper lateral incisors, which corroborates results of the present study. As trauma affects anterior teeth, studies highlighted the negative impact on quality of life in terms of physical and psychological discomfort, in addition to the high potential for negative interference in social relationships such as aesthetics impairment and psychological problems, making the affected individual to avoid talking and smiling, in addition to functional difficulties such as biting or chewing [21,22].

The etiology and location of accidents that resulted in dental trauma were investigated through participants' self-report. Falls on the streets were the main causes of dental trauma. Fall was the main etiological factor reported in studies that investigated etiological factors $[4,5,8,16,20]$. In a recent retrospective study in children under 5 years of age, falls were also observed as the most prevalent etiological factor (64.4\%) [8]. Although in the present study no case of trauma was associated with situations of violence, many of these falls may be the result of acts of aggression, thus, intentional trauma could be underestimated [23-25]. Regarding the accident site, controversial results have been reported. In the city of Herval D'Oeste, the main accident site was the school [7], differing from this study where the highest occurrence was observed in the streets. Probably, the place of occurrence can be explained by cultural and geographical aspects. Diamantina is a country town with emphasis on cultural and tourist aspects. It offers satisfactory security with municipal guards protecting its historical heritage and, consequently, its population. Thus, children and adolescents still have fun playing in the streets and frequently walk to schools. However, some factors such as its rugged relief and central streets with typical paving of irregular stones must be considered, which could lead to greater occurrence of accidents, unlike other locations [26].

Most interviewees did not remember the place where the trauma occurred or its etiology. This can be explained by the fact that most lesions affected the enamel, often imperceptible and, when added to the presence of bodily injuries, would result in not seeking immediate dental treatment [23]. Thus, it is necessary to create and monitor safe environments for children and adolescents, to provide information to parents and teachers both for preventive actions and for handling dental trauma in order to minimize its prevalence, as well as its sequelae [24].

Only 39 adolescents $(22.2 \%)$ received dental care. This result is superior to other studies carried out in Brazil, such as Palhoça [20], with $6.60 \%$ and Biguaçu [19] with $15.60 \%$ of adolescents who received dental care.

It is important to consider that most dental injuries in the present study occurred in the form of enamel cracks and fractures, requiring, in most cases, no type of restorative treatment, therefore reflecting in lower percentage of dental care received, which needs proservation, as sequelae may appear later [1]. However, the study points out that the Public Health System is still unable to meet all of the demand, either due to the need for more educative actions to inform the population about dental trauma and its consequences, 
or due to the low number of dentists in the network. Immediate care for the traumatized patient is crucial to establish a positive prognosis; moreover, injuries can be more critical than they clinically appear to be [4].

Hospital care intervenes in cases of polytrauma, and when it comes to dental fractures, the patient should seek a dentist in a specialized dental office [27]. Other factors that could also be associated with low treatment rate are the fear that many people have about dental treatment and the low socioeconomic conditions, which make the search for treatment unfeasible. The literature also highlights that the neglect of treatment may be a consequence of the low level of knowledge of dentists regarding the management of dental trauma and its proservation [27-28]. In a study assessing the level of knowledge of dentists in Rio Grande do Sul on the management of traumatic dental injuries, it was concluded that the general level of knowledge of professionals about the guidelines of the International Association of Dental Traumatology (IADT) is moderate, highlighting the need for continuing education on dento-alveolar trauma [29]. A literature review with the aim of evaluating the extent of physicians' knowledge on dental trauma management for lesions of the dental structure, supporting bones, periodontium and soft tissues, showed deficiency in knowledge and confidence in the treatment of dental trauma, justifying the intervention of educators [13].

The fact that the majority of the Brazilian population is considered socially and economically vulnerable and the difficulty of scheduling dental treatment in public services, may contribute to the low number of restorative treatments observed in this study [21].

Of the 176 adolescents who suffered dental trauma, 94 (56.4\%) needed restorative treatment and the majority had indication of composite resin restoration. These treatments are of low complexity and are available in public dental services. However, when radiographies are indicated for treatment and control and endodontic treatment prior to restorative treatment, the difficulty of accessing public health services is even greater due to its complexity not yet met by Dental Specialties Centers (CEO). In 2016, less than half of municipalities in the southern region of Brazil had dental radiographic equipment, and among those who had such equipment, half did not perform any procedure [30]. In other regions of the country, CEOs show service disorganization at different levels of care, impairing the integrality of care and overloading the health care network [14], in addition to waiting time for inadequate endodontic treatment and flows that do not follow defined standards [31].

The results of this study showed that maternal schooling over 8 years was associated with greater need for restorative treatment. This result corroborates study carried out in Biguaçu, Brazil [19]. Lower maternal schooling was associated with worse quality of life related to oral health in adolescents, living in urban areas [32] and in rural areas [33]. Some authors suggest the need for female presence in the labor market, which would culminate in the delegation of childcare to third parties [34]. Thus, literature highlights the conflict of results, requiring further studies to establish the behavior of this variable in relation to oral health.

Health professionals must be prepared to identify and advise parents / guardians on the best measures to be adopted after dental trauma. The lack of treatment at the right time and the need for follow-up for a longer period of time can also lead to complications such as changes in color, mobility, dental arch, painful symptoms, sensitivity, internal and external root resorption, necrosis and loss of the dental element, which can lead to difficulties in social interaction, low self-esteem and problems with future relationships, especially in the absence of the dental element [4].

Comparing the results of studies involving the population is extremely difficult, since there is no uniformity of methodologies [16,19]. Thus, further studies should be developed with standardized protocol, so that comparisons can be made through analysis of their data. 
The limitations of the present study must be considered and mainly result from memory bias, probably present when interviewees reported information regarding the conditions in which dental trauma occurred. Thus, a more accurate report should be obtained through more judicious approach evaluating, for example, access to restorative treatment.

\section{Conclusion}

The need for restorative treatment in a considerable number of adolescents affected by dental trauma who did not have access to restorative treatment points to the poor preventive profile of health systems, as well as their inefficiency in absorbing all the dental treatment demand presented in this portion of the population.

\section{Authors' Contributions}

\begin{tabular}{|c|c|c|}
\hline HNP & (iD) $0000-0002-4476-8842$ & Investigation and Writing - Original Draft Preparation. \\
\hline CMPA & (iD) $0000-0001-6012-9058$ & Investigation and Writing - Original Draft Preparation. \\
\hline KBS & (iD) $0000-0002-9462-2315$ & Investigation and Writing - Original Draft Preparation. \\
\hline TTVS & (iD) $0000-0001-7198-4981$ & Investigation and Writing - Original Draft Preparation. \\
\hline PMOF & (iD) $0000-0002-1725-5531$ & Writing - Review and Editing. \\
\hline PCPP & (iD) $0000-0002-5960-4760$ & $\begin{array}{l}\text { Conceptualization, Methodology, Formal Analysis and Writing - Review and } \\
\text { Editing. }\end{array}$ \\
\hline
\end{tabular}

\section{Financial Support}

None.

\section{Conflict of Interest}

The authors declare no conflicts of interest.

\section{References}

[1] Andreasen JO, Andreasen FM, Anderson L. Textbook and Color Atlas of Traumatic Injuries to the Teeth. 4th ed. Oxford: Blackwell, 2007.

[2] Andersson L. Epidemiology of traumatic dental injuries. J Endod 2013; 39(1):S2-5. https://doi.org/10.1016/j.joen.2012.11.021

[3] Aldrigui JM, Jabbar NS, Bonecker M, Braga MM, Wanderley MT. Trends and associated factors in prevalence of dental trauma in Latin America and Caribbean: a systematic review and meta-analysis. Community Dent Oral Epidemiol 2014; 42(1):30-42. https://doi.org/10.1111/cdoe.12053

[4] Mamaladze M, Nizharadze N, Vadachkoria O. The peculiarities of treatment of uncomplicated and complicated injuries caused by trauma. Georgian Med News 2017; 262:28-32.

[5] Zaleckiene V, Peciuliene V, Brukiene V, Drukteinis S. Traumatic dental injuries: etiology, prevalence and possible outcomes. Stomatologija 2014; 16(1):7-14.

[6] Glendor U. Aetiology and risk factors related to traumatic dental injuries - a review of the literature. Dent Traumatol 2009; 25(1):19-31. https://doi.org/10.1111/j.1600-9657.2008.00694.x

[7] Traebert J, Bittencourt DD, Peres KG, Peres MA, Lacerda JT, Marcenes W. Aetiology and rates of treatment of traumatic dental injuries among 12-year-old school children in a town in southern Brazil. Dent Traumatol 2006; 22(4):173-8. https://doi.org/10.1111/j.1600-9657.2006.00359

[8] Ng L, Malandris M, Cheung W, Rossi-Fedele G. Traumatic dental injuries presenting to a paediatric emergency department in a tertiary children's hospital, Adelaide, Australia. Dent Traumatol 2020; https://doi.org/10.1111/edt.12548

[9] Azami-Aghdash S, Ebadifard Azar F, Pournaghi Azar F, Rezapour A, Moradi-Joo M, Moosavi A, et al. Prevalence, etiology, and types of dental trauma in children and adolescents: systematic review and meta-analysis. Med J Islam Repub Iran 2015; 29(4):234.

[10] Paiva PC, Paiva HN, Jorge KO, Oliveira Filho PM. Cross-sectional study on treatment needs, etiology and occurrence of traumatic dental injuries among 12-yearold schoolchildren in Montes Claros, Brazil. Arq Odontol 2013; $49(1): 19-25$. 
[11] Paiva HN, Paiva PCP, Silva CJP, Lamounier JA, Ferreira EF, Ferreira R, Kawachi I, Zarzar PM. Is there an association between traumatic dental injury and social capital, binge drinking and socioeconomic indicators among schoolchildren? Plos One 2015; 10(2):e0118484. https://doi.org/10.1371/journal.pone.0118484.eCollection 2015

[12] Bauss O, Freitag S, Röhling J, Rahman A. Influence of overjet and lip coverage on the prevalence and severity of incisor trauma. J Orofac Orthop 2008; 69(6):402-10. https://doi.org/10.1007/s00056-008-8805-1

[13] Dental Yeng T, O'Sullivan AJ, Shulruf B. Medical doctors' knowledge of dental trauma management: a review. Dent Traumatol 2020; 36(2):100-7 https://doi.org/10.1111/edt.12518

[14] Correia TRGS, Pessoa DMV. Performance evaluation of dental care specialties centers of the Seridó Potiguar from 2012 to 2017. Rev Cienc Plur 2019; 5(3):54-71.

[15] Glendor U, Jonsson D, Halling A, Lindqvist K. Direct and indirect costs of dental trauma in Sweden: a 2-year prospective study of children and adolescents. Community Dent Oral Epidemiol 2001; 29(2):150-60.

[16] Enabulele JE, Oginni AO, Sede MA, Oginni FO. Pattern of traumatized anterior teeth among adult Nigerians and complications from late presentation. BMC Res Notes 2016; 9:70. https://doi.org/10.1186/s13104-016-1871-3

[17] Instituto Brasileiro de Geografia e Estatistica. Demographic Census 2015. Dados dos distritos MG. Available from: <http://www.bnb.gov.br/content/aplicacao/prodetur/downloads/docs/mg_7_2_inventar_oferta_turistica_informac _basica_distrito_100708.pdf $>$. [Accessed on July 28, 2017]. [In Portuguese]

[18] World Health Organization. Oral Health Surveys: Basic Methods. 4th ed. Geneva: WHO; 1997

[19] Traebert J, Almeida IC, Garghetti C, Marcenes W. Prevalence, treatment needs, and predisposing factors for traumatic injuries to permanent dentition in 11-13-year-old schoolchildren. Cad Saúde Pública 2004; 20(2):403-10.

[20] Traebert J, Marcon KB, Lacerda JT. Prevalence of traumatic dental injuries and associated factors in schoolchildren of Palhoça, Santa Catarina State. Cien Saude Coletiva 2010; 15(Suppl 1):1849-55. https://doi.org/10.1590/S1413-81232010000700098

[21] Antunes LA, Leão AT, Maia LC. The impact of dental trauma on quality of life of children and adolescents: a critical review and measurement instruments. Cien Saude Coletiva 2012; 17(12):3417-24. https://doi.org/10.1590/S1413-81232012001200026

[22] Silva-Oliveira F, Goursand D, Ferreira RC, Paiva PCP, Paiva HN, Ferreira EF, et al. Traumatic dental injuries in Brazilian children and oral health-related quality of life. Dent Traumatol 2018; 34(1):28-35. https://doi.org/10.1111/edt.12358

[23] Coulthard P, Yong SL, Adamson L, Warburton A, Worthington HV, Esposito M, et al. Domestic violence screening and intervention programmes for adults with dental or facial injury. Cochrane Database Syst Rev 2015; 2015:CD004486. https://doi.org/10.1002/14651858.CD004486.pub4

[24] Marcenes W, Al Beiruti N, Tayfour D, Issa S. Epidemiology of traumatic injuries to the permanent incisors of 9-12year-old schoolchildren in Damascus, Syria. Endod Dent Traumatol 1999; 15(3):117-23.

[25] Ferreira MC, Batista AM, Ferreira F de O, Ramos-Jorge ML, Marques LS. Pattern of oral-maxillofacial trauma stemming from interpersonal physical violence and determinant factors. Dent Traumatol 2014; 30(1):15-21. https://doi.org/10.1111/edt.12047

[26] Paiva PCP, Paiva HN, Filho PMO, Lamounier JA, Zarzar PM. Exploratory study on the prevalence of dental injuries and obesity among 12-years-old schoolchildren in Diamantina, Minas Gerais, Brazil. Arq Odontol 2013; 50(1):35-41.

[27] Panzarini SR, Saad Neto M, Sonoda CK, Poi WR, Carvalho AC. Dental avulsion in young and adult patients in the region of Araçatuba. Rev Assoc Paul Cir Dent 2003; 57(1):27-31.

[28] Hamilton FA, Hill FJ, Mackie IC. Investigation of lay know ledge of the management of avulsed permanent incisors. Endod Dent Traumatol 1997; 13(1):19-23.

[29] Hartmann RC, Rossetti BR, Siqueira Pinheiro L, Poli de Figueiredo JA, Rossi-Fedele G, S Gomes M, et al. Dentists' knowledge of dental trauma based on the International Association of Dental Traumatology guidelines: a survey in South Brazil. Dent Traumatol 2019; 35(1):27-32. https://doi.org/10.1111/edt.12450

[30] Chisini LA, San Martin AS, Silva JVJBF, Brambatti N, Pietro FS, Conde MCM, et al. Brazilian National Health System dental x-ray coverage in Southern Brazil in 2016: an ecological study. Epidemiol Serv Saude 28(1):e2018090 https://doi.org/10.5123/S1679-49742019000100005

[31] Roque EM, Leitão HS, Alves ICR, Cadorin ES, Bezerras IMP. Therapeutic itineraries: knowing the user access trajectory for specialized treatment endodontity in the Rio Branco municipal health network - Acre. DeCien em Foco $2019 ; 3(2): 47-66$.

[32] Feldens CA, Senna RA, Vargas-Ferreira F, Braga VS, Fendens EG, Kramer PF. The effect of enamel fractures on oral health-related quality of life in adolescents. Dent Traumatol 2019; https://doi.org/10.1111/3et.12526

[33] Reis AG, Paiva PCP, Oliveira Filho PM. Prevalence of dental trauma and associated factors in 11 to 19-year-old students in the rural areas of the town of Diamantina, MG, Brazil. Arq Odontol 2014; 50(1):42-8.

[34] Corrêa-Faria P, Martins CC, Bönecker M, Paiva SM, Ramos-Jorge ML, Pordeus IA. Clinical factors and sociodemographic characteristics associated with dental trauma in children: a systematic review and meta-analysis. Dent Traumatol 2016; 32(5):367-78. https://doi.org/10.1111/edt.12268 